\title{
Induction of labour after 37 weeks of pregnancy using foley's catheter: traction versus non-traction method
}

\author{
Jaydeep J. Bhatu*, Disha Patel
}

Department of Obstetrics and Gynaecology, GMERS Medical College and Hospital, Junagadh, Gujarat, India

Received: 30 October 2020

Revised: 15 December 2020

Accepted: 16 December 2020

*Correspondence:

Dr. Jaydeep J. Bhatu,

E-mail: bhatujaydeep@gmail.com

Copyright: (c) the author(s), publisher and licensee Medip Academy. This is an open-access article distributed under the terms of the Creative Commons Attribution Non-Commercial License, which permits unrestricted non-commercial use, distribution, and reproduction in any medium, provided the original work is properly cited.

\section{ABSTRACT}

Background: Cervical Foley's catheter used now a days for induction of labour alone as well as a combined with cerviprim gel. The objective of the study was to assess the effectiveness of $750 \mathrm{cc}$ traction on Foley catheter with no traction for labour induction in $>37$ weeks pregnancy.

Methods: A randomized controlled trial performed on pregnant women at $>37$ weeks who were admitted for induction of labour with unfavourable cervix. They were randomly assigned into two groups, Foley's with 750 cc traction and without traction. The primary outcomes were improvement in Bishop Score, number of favourable cervix following induction and the mode of delivery. The secondary outcomes were neonatal outcome, and maternal infection.

Results: A total of 80 pregnant women were randomized into traction group $(n=46)$ and non-traction group ( $n=34)$. Traction group had significantly $(\mathrm{p}=0.0462)$ higher number of vaginal delivery compared to non-traction group. Participants were comfortable using both methods. There was no difference in neonatal outcomes and risk of maternal infections in both groups.

Conclusions: Application of traction did result in more vaginal delivery.

Keywords: Foley’s induction, Induction of labour, Bishops score, Chorioamnionitis, Cerviprim gel, APGAR score

\section{INTRODUCTION}

Cervical Foley's catheter used now a days for induction of labour alone as well as a combined with cerviprim gel. Induction of labour (IOL) is a most commonly used procedure in obstetrics, occurring in up to $25 \%$ of pregnancies in India. ${ }^{1}$ Methods of induction of labour include either mechanical or pharmacological. The ideal method for cervical ripening should be safe for both fetus and mother, cost effective, and does not require extensive monitoring. Trans cervical Foley catheter for cervical ripening was first described by Embrey. ${ }^{2}$ The catheter works by mechanically stretching the cervical canal and causes release of prostaglandin which results in cervical changes.
The guidelines of SOGS state a Foley catheter may be safely used to ripen the cervix in a woman planning a trial of labour after Caesarean section. ${ }^{3}$ In contrast, the ACOG believe that, given a lack of compelling data and the increased risk of mechanical dilatation, such interventions should only be an option for trial of VBAC delivery among candidates with an unfavourable cervix. Main objective of the study to justify neither the use of Foley's catheter induction with traction is more helpful in improving the bishop score or not.

\section{Aims and objectives}

Primary objective is to improvement in Bishop score and number of favorable cervix following induction and the mode of delivery assessment and the secondary objective 
is neonatal outcome and maternal infection after Foley's induction.

\section{METHODS}

Present study is a randomized controlled trial study which involved 80 pregnant women between 37 to 41 weeks with unfavorable cervix (Bishop Score $\leq 5 / 13$ ) who were admitted for induction of labor between January 2019 till December in SOLA civil hospital.

The study was approved by the local medical ethics review board.

Exclusion criteria were women with closed cervical os, ruptured membrane, multiple pregnancy, two previous caesarean scars or more, fetal malpresentation, maternal infections, polyhydramnions and presence of signs or symptoms of maternal and fetal compromise. All patients were provided with written informed consent.

All women who were admitted for IOL after screened for eligibility.

After getting the informed consent, they were randomized by computer software to either group A (with traction) or group B (without traction).

Cervical assessment was performed by senior obstetrician with modified Bishop score. In present study, Foley catheter with size $18 \mathrm{G}$ was used and inflated with $75 \mathrm{cc}$ normal saline.

It was inserted by senior obstetrician under aseptic technique and total $750 \mathrm{cc}$ pint traction applied in group A and in the group B the distal part of catheter was anchored to the right thigh using a strap to allow easy ambulation. The Foley catheters were either dislodged spontaneously or removed within 24 hours.

Reassessment of cervical scoring was then performed by senior obstetrician. Bishop score of more than 8 was considered favourable. Women with favourable cervix were then sent to delivery suite for artificial rupture of membrane following the local protocol. Prostaglandin E2 (PGE2) was inserted in women whose cervices remain unfavourable following Foley catheter. Antibiotic, analgesia and oxytocin were given according to local protocol. Women were monitored for any side effects of mechanical induction. Neonatal outcomes which include Apgar score at 1 and 5 minutes of life and admission to Neonatal intensive care unit (NICU) or neonatal infection were recorded. Post-delivery, all women were monitored for signs of infection.

The primary outcomes were improvement in Bishop Score, number of favourable cervix following induction and the mode of delivery. The secondary outcomes were neonatal outcome, and maternal infection.

\section{Statistical analysis}

All data was analyzed using Statistical package for social sciences (SPSS) version 20.0. Descriptive data were expressed as mean, median, standard deviation (SD) or percentage. Comparisons between groups were performed with Chi-square, independent t-test, Mann-Whitney and Fisher's Exact test. P value of less than 0.05 is considered as statistically significant.

\section{RESULTS}

Table 1 shows that total vaginal delivery in traction Foley's induction group were $62.5 \%$ which was higher than non-traction group and it also statistically significant $(p=0.0462)$. There is lower rate of caesarean delivery in group A compare to non-traction group.

Table 1: Difference in Bishop Score and mode of delivery based on cervical favourability in the two groups.

\begin{tabular}{|c|c|c|c|}
\hline \multirow[t]{2}{*}{ Mode of delivery } & Group A & Group B & \multirow{2}{*}{$\begin{array}{l}\mathbf{P} \\
\text { value }\end{array}$} \\
\hline & & & \\
\hline $\begin{array}{l}\text { Total vaginal } \\
\text { delivery }\end{array}$ & $40(62.5)$ & $24(37.5)$ & 0.0462 \\
\hline $\begin{array}{l}\text { Caesarean } \\
\text { section }\end{array}$ & $6(20)$ & $\begin{array}{l}10 \\
(29.17)\end{array}$ & 0.6941 \\
\hline \multicolumn{4}{|l|}{$\begin{array}{l}\text { Indication of } \\
\text { caesarean } \\
\text { section }\end{array}$} \\
\hline Fetal distress & 5 & 3 & \\
\hline Poor progress & 2 & 2 & \\
\hline Failed IOL & 1 & 2 & \\
\hline
\end{tabular}

Table 2: Mode of delivery in both method groups.

\begin{tabular}{|llll|}
\hline Parameter & \multicolumn{1}{c}{$\begin{array}{c}\text { Group } \\
\mathbf{N}(\%)\end{array}$} & $\begin{array}{l}\text { Group } \\
\mathbf{B}(\%)\end{array}$ & $\begin{array}{l}\text { P } \\
\text { value }\end{array}$ \\
\hline $\begin{array}{l}\text { Mean } \\
\text { difference in } \\
\text { Bishop score }\end{array}$ & 4.90 & 4.0 & \\
\hline $\begin{array}{l}\text { Favorable } \\
\text { cervix }\end{array}$ & $35(76 \%)$ & $25(73.5 \%)$ & 0.8270 \\
\hline $\begin{array}{l}\text { Vaginal } \\
\text { delivery }\end{array}$ & $32(69 \%)$ & $20(58.8 \%)$ & 0.457 \\
\hline $\begin{array}{l}\text { Caesarean } \\
\text { section }\end{array}$ & $3(6.5 \%)$ & $5(14.7 \%)$ & 0.743 \\
\hline $\begin{array}{l}\text { Unfavorable } \\
\text { cervix }\end{array}$ & $11(23.9 \%$, & $9(26.5 \%)$ & 0.896 \\
\hline $\begin{array}{l}\text { Vaginal } \\
\text { delivery }\end{array}$ & $8(17.4 \%)$ & $4(11.8 \%)$ & 0.809 \\
\hline $\begin{array}{l}\text { Caesarean } \\
\text { section }\end{array}$ & $3(6.5 \%)$ & $5(14.7 \%)$ & 0.74 \\
\hline
\end{tabular}


Table 2 shows that there is higher vaginal delivery percentage in favourable as well as unfavourable cervix in group a compare to group b also, there is lower caesarean percentage in traction Foley's induction group although data were not statistically significant so there was no significance demonstrated.

Table 3: Neonatal clinical characteristics in two groups.

\begin{tabular}{|c|c|c|c|}
\hline Parameters & $\begin{array}{l}\text { Group A } \\
\mathbf{N}(\%)\end{array}$ & $\begin{array}{l}\text { Group B } \\
\mathbf{N}(\%)\end{array}$ & $P$ value \\
\hline \multicolumn{4}{|c|}{ Baby birth weight (kg) } \\
\hline$<2.5$ & $6(13.04)$ & $8(23.52)$ & 0.633 \\
\hline $2.6-3.0$ & $34(73.9)$ & $23(67.6)$ & 0.608 \\
\hline $3.1-3.5$ & $6(13.04)$ & $3(8.82)$ & 0.860 \\
\hline $\begin{array}{l}\text { Apgar score } \\
\text { at } 1 \text { and } 5 \\
\text { minutes } \\
\text { (mean) }\end{array}$ & $8 / 9$ & $7 / 9$ & \\
\hline $\begin{array}{l}\text { NICU } \\
\text { admission }\end{array}$ & $3(6.5)$ & $5(14.7)$ & 0.74 \\
\hline
\end{tabular}

Table 3 shows that there is higher favourable delivery of more than $3 \mathrm{~kg}$ weight baby in traction Foley's group comparison to group B.

\section{DISCUSSION}

The purpose of induction is to achieve vaginal delivery within a short time, and shorter induction to delivery interval is associated with lower costs and reduced risks of chorioamionitis.

A prospective RCT in 140 women by Fruhmam et al comparing induction of labor using trans cervical catheter with or without traction followed by low dose oxytocin administration showed that there were no significant difference in terms of vaginal delivery between both groups $(79 \%$ versus $71 \%, \mathrm{p}=0.365) .{ }^{4}$ The data from this study showed that placement of $750 \mathrm{cc}$ traction on Foley catheter during induction had more successful vaginal delivery compared to without traction (62.5 versus $37.5 \%$, $\mathrm{p}=0.0462$ ). The mean change in Bishop score was similar in both methods.

Cromi et al reported that cutting the maximum time for cervical. Ripening from 24 to 12 hours would significantly shorten the induction to delivery interval and yield efficacy similar to that of prostaglandin E2 vaginal insert (delivery within 24 hours induction:24-hour Foley catheter, 21.0\%; 12-hour Foley catheter, 59.8\%; vaginal prostaglandin E2,48.5\%). ${ }^{5}$ In this study Foley catheter left in place for up to 12 hours brings about cervical changes sufficient for term labor induction, and shorter ripening time is associated with earlier artificial rupture of the membranes and start of oxytocin augmentation, which might be related to quicker labor onset.
A randomized study on 45 women by Lutgendorf et al comparing taping Foley catheter to women's thigh versus Foley catheter with tension using $1 \mathrm{~L}$ bag of fluid placed to gravity showed the mean time to expulsion was shorter in the tension group $(\mathrm{p}=0.001){ }^{6}$

Another randomized controlled trial by Gibson et al on 197 women compared the effectiveness of inner thigh taping with traction using a $500 \mathrm{ml}$ weighted bag. Traction did shorten the time to spontaneous catheter expulsion $(\mathrm{p}<0.001)$ without affecting the time to delivery. ${ }^{7}$ Change in Bishop score and pain score were similar between group. In this study, the use of $750 \mathrm{cc}$ traction resulted in more favorable cervix. Even though it was not statistically significant, it significantly increased the rate of vaginal delivery.

Mechanical IOL in women with previous caesarean section due to non- recurrent cause was safe and most often successful; therefore help to reduce repeat caesarean section. $^{8}$

The use of Foley catheter for cervical ripening increase the risk of chorioamnionitis remained controversial, However, a meta-analysis on 26 randomized trials by Mcmaster et al revealed that there is a similar rate of chorioamnionitis between cervical ripening with Foley catheter versus PGE2 (relative risk [RR] 0.96; 95\% confidence interval [CI] 0.66-1.38). ${ }^{9}$

This study showed that there was no difference in neonatal outcomes and risk of maternal infection.

In Misoprostol group, patients were with thick meconium stained liquor. ${ }^{10}$ Where in Foley's induction less chances of meconium development.

Limitations of the study are, it's a moreover subjective analysis and induction.

\section{CONCLUSION}

This study concluded that there is no significant reduction in $750 \mathrm{cc}$ reduction group but there is increase in vaginal delivery which was also statistically significant as also there are no chances of maternal infection of chorioamnionitis and neonatal infection Foley's induction with traction preferred.

Funding: No funding sources

Conflict of interest: None declared

Ethical approval: The study was approved by the Institutional Ethics Committee

\section{REFERENCES}

1. Mundle S, Bracken H, Khedikar V, Mulik J, Faragher B, Easterling T et al. Foley catheterisation versus oral misoprostol for induction of labour in hypertensive women in India (INFORM): a multicentre, open- 
label, randomised controlled trial. The Lancet. 2017;390(10095):669-80.

2. Embrey MP, Mollison BG. The unfavourable cervix and induction of labour using a cervical balloon. BJOG: An International Journal of Obstetrics \& Gynaecology. 1967;74(1):44-8.

3. Martel MJ, MacKinnon CJ, Martel MJ. Clinical Practice Obstetrics Committee of the Society of Obstetricians and Gynaecologiests of Canada. Guidelines for vaginal birth after previous Caesarean birth. J Obstet Gynaecol Can. 2004;26(7):660-83.

4. Fruhman G, Gavard JA, Amon E, Flick KV, Miller C, Gross GA. Tension compared to no tension on a Foley transcervical catheter for cervical ripening: a randomized controlled trial. American Journal of Obstetrics and Gynecology. 2017;216(1):67-e1.

5. Cromi A, Ghezzi F, Agosti M, Serati M, Uccella S, Arlant V et al. Is transcervical Foley catheter actually slower than prostaglandins in ripening the cervix? A randomized study. American journal of obstetrics and gynecology. 2011;204(4):338-e1.

6. Lutgendorf MA, Johnson A, Terpstra ER, Snider TC, Magann EF. Extra-amniotic balloon for preinduction cervical ripening: a randomized comparison of weighted traction versus unweighted. The Journal of
Maternal-Fetal \& Neonatal Medicine. 2012;25(6):581-6.

7. Gibson KS, Mercer BM, Louis JM. Inner thigh taping vs traction for cervical ripening with a Foley catheter: a randomized controlled trial. American journal of obstetrics and gynecology. 2013;209(3):272-e1.

8. Iqbal S, Shuja S, Fatima N. Outcome of induction of labour with intracervical Foley catheter in women with previous one caesarean section. Journal of Surgery Pakistan (International). 2015;20(2):44-7.

9. McMaster K, Sanchez-Ramos L, Kaunitz AM. Evaluation of a transcervical Foley catheter as a source of infection: a systematic review and metaanalysis. Obstetrics \& Gynecology. 2015;126(3):53951.

10. Bhatu JJ, Chaudhari AB, Chauhan NR. Oxytocin versus Misoprostol used as an induction of labour in term in early rupture of Amniotic membranes. Int $\mathbf{J}$ Reprod Contracept Obstet Gynecol 2020;9:1023-8.

Cite this article as: Bhatu JJ, Patel D. Induction of labour after 37 weeks of pregnancy using foley's catheter: traction versus non-traction method. Int $\mathbf{J}$ Reprod Contracept Obstet Gynecol 2021;10:275-8. 